\title{
Bilateral Phrenic Nerve Paralysis Manifested by Orthopnea for 6 Months in a Patient with Neuralgic Amyotrophy
}

\author{
Gaku Ikegami, Tokuro Abe, Keiichi Akasaka, Akemi Kouyama, Ryosuke Souma, \\ Takashi Matsuo, Kenya Kouyama, Hiroki Fujiwara, Toshio Ichiwata and Koshu Nagao
}

\begin{abstract}
Bilateral phrenic nerve paralysis (BPP) is a relatively rare disease manifested by slight dyspnea at rest and on exertion in the sitting and standing positions and by dyspnea in the supine position. A 67-year-old man, who was a painter presented with severe pain in both shoulder regions that had evolved into orthopnea and forced him to sleep in a sitting position at night. Dyspnea and paradoxical respiratory movement in the supine position raised suspicions of BPP. The most striking feature in this case was that the rapid onset of pain in both shoulder regions was followed by BPP. The BPP was considered to be secondary to neuralgic amyotrophy (NA).
\end{abstract}

Key words: bilateral phrenic nerve paralysis, neuralgic amyotrophy, orthopnea, paradoxical breathing, gravity

(Inter Med 48: 2123-2127, 2009)

(DOI: 10.2169/internalmedicine.48.1266)

\section{Introduction}

Orthopnea can be a sign of acute left heart failure or bronchial asthma attack. And respiratory muscle paralysis and bilateral phrenic nerve paralysis (BPP) also result in dyspnea in the supine position. BPP is a rare disease, characterized by dyspnea, developing immediately after changing the body position from sitting to a supine position (indicating orthopnea) and by paradoxical respiratory movement. The diagnosis is made based on the absence of bilateral diaphragmatic contraction in response to percutaneous phrenic nerve stimulation (1). Many cases of BPP are attributed to be due to neuropathy (1), but many other cases remain unidentified and often prove difficult to diagnose. We describe our experience with a BPP patient who complained of dyspnea and was forced to resume the sitting position after only a few minutes of lying down. Since BPP occurred a few days after pain in both shoulders, neuralgic amyotrophy (NA) was considered to be the cause in this case.

\section{Case Report}

A 67-year-old man who was a painter had the chief com- plaint of dyspnea in the supine position. He had had an appendectomy at the age of 20 and he had smoked 10 cigarettes a day for 46 years, but did not regularly consume alcohol.

He went on a sketching trip from early May 1996 and walked carrying heavy painting materials on his shoulders. He experienced severe pain in both shoulders at night on the third day, but the pain subsided the following day. Seven days later, he became aware of breathing difficulties at night in the supine position, and after 10 days he began to experience the same symptoms when in the bathtub. He visited a local doctor, but no diagnosis was reached. And for 7 months he slept in a sitting position because of the inability to remain in the supine position for more than a few minutes at a time. He was referred to our hospital and was admitted for a work-up in early December 1996.

Findings from physical examination on admission: height $166.4 \mathrm{~cm}$, body weight $69 \mathrm{~kg}$, blood pressure 138/78 $\mathrm{mmHg}$, respiratory rate $20 / \mathrm{min}$ and regular, pulse rate $80 /$ min, lucid consciousness, no anemia or jaundice, no palpable mass in the neck, and no edema. No cyanosis was noted. No abnormalities were found in cardiac/breathing sounds. No clubbed fingers or palpable superficial lymph nodes were found. There were no abnormal dermal findings. 
Table 1. Laboratory Findings

\begin{tabular}{|c|c|c|c|c|c|c|}
\hline \multicolumn{4}{|c|}{ - Hematology } & \multicolumn{3}{|c|}{ Biochemistry } \\
\hline WBC & 5600 & \multicolumn{2}{|l|}{$/ \mu \mathrm{L}$} & GOT & 22 & $\mathrm{IU} / \mathrm{L}$ \\
\hline $\mathrm{RBC}$ & 466 & \multicolumn{2}{|c|}{$\times 10^{4} / \mu \mathrm{L}$} & GPT & 27 & $\mathrm{IU} / \mathrm{L}$ \\
\hline $\mathrm{Hb}$ & 14.7 & \multicolumn{2}{|c|}{$\mathrm{g} / \mathrm{dL}$} & ALP & 154 & $\mathrm{IU} / \mathrm{L}$ \\
\hline $\mathrm{Ht}$ & 43.6 & \multicolumn{2}{|l|}{$\%$} & $\mathrm{LDH}$ & 337 & $\mathrm{IU} / \mathrm{L}$ \\
\hline Plt & 18.1 & \multicolumn{2}{|c|}{$\times 10^{4} / \mu \mathrm{L}$} & $\gamma$ GTP & 20 & $\mathrm{IU} / \mathrm{L}$ \\
\hline $\mathrm{PT}$ & 12.4 & \multicolumn{2}{|c|}{ sec } & BUN & 16 & $\mathrm{mg} / \mathrm{dL}$ \\
\hline APTT & 25.9 & \multicolumn{2}{|l|}{$\mathrm{sec}$} & $\mathrm{Cr}$ & 1.0 & $\mathrm{mg} / \mathrm{dL}$ \\
\hline \multirow{2}{*}{\multicolumn{4}{|c|}{ Arterial blood Gas }} & $\mathrm{Na}$ & 143 & $\mathrm{mEq} / \mathrm{L}$ \\
\hline & & & & $\mathrm{K}$ & 3.7 & $\mathrm{mEq} / \mathrm{L}$ \\
\hline & $\begin{array}{l}\text { position } \\
\text { (Dec 1996) }\end{array}$ & \multicolumn{2}{|l|}{$\begin{array}{r}\text { position } \\
\text { (Jan 1997) }\end{array}$} & $\mathrm{Cl}$ & 102 & $\mathrm{mEq} / \mathrm{L}$ \\
\hline $\mathrm{pH}$ & 7.438 & \multicolumn{2}{|l|}{7.416} & \multirow{4}{*}{$\mathrm{CK}$} & 87 & $\mathrm{mg} / \mathrm{dL}$ \\
\hline $\mathrm{PaCO}_{2}$ & 39.2 & 41.6 & Torr & & \multirow[t]{3}{*}{61} & \multirow[t]{3}{*}{ IU/L } \\
\hline $\mathrm{PaO}_{2}$ & 93.2 & 60.5 & Torr & & & \\
\hline $\mathrm{HCO}_{3}{ }^{-}$ & 25.9 & 26.1 & $\mathrm{mEq} / \mathrm{L}$ & & & \\
\hline
\end{tabular}
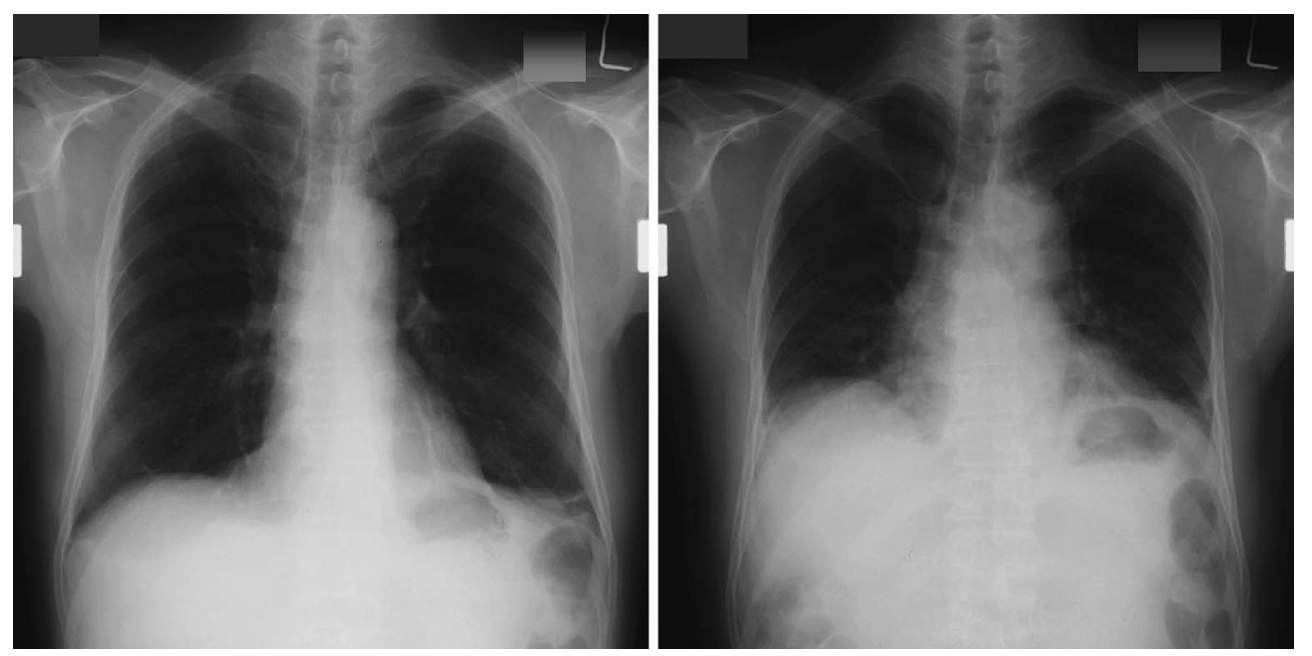

Figure 1. Chest $X$-rays in the standing position at the first visit in early December, 1996: (A) Mild discoid atelectasis in the left lower lobe on deep inspiration. (B) The diaphragm is elevated approximately $5 \mathrm{~cm}$ on deep expiration in comparison to deep inspiration.

Findings from laboratory examination on admission are shown in Table 1. There were no abnormalities in blood count or biochemistry. When blood gases were taken in the sitting position, $\mathrm{PaO}_{2}$ was 93.2 Torr, and $\mathrm{PaCO}_{2}$ was 39.2 Torr.

Image findings: Discoid atelectasis was observed just above the left diaphragm on the chest X-ray taken in the standing position on admission. The diaphragm level was elevated approximately $5 \mathrm{~cm}$ at expiration in comparison to inspiration, so the respiratory movement of the diaphragm was considered to be normal (Fig. 1).

Respiratory function test: The patient successfully completed a respiratory function test (CHESTAC-55V: CHEST, Tokyo, Japan) in the sitting position in early December, with findings in the sitting position as follows: \%vital capacity (\%VC) of $76.1 \%$ (2), forced expiratory volume in one second/forced vital capacity $\left(\mathrm{FEV}_{1.0} / \mathrm{FVC}\right)$ of $78.7 \%$, \% maximal voluntary ventilation (\%MVV) of $74 \%$ (Baldwin), and \%diffusing capacity for carbon monoxide $\left(\% \mathrm{DL}_{\mathrm{co}}\right)$ of $96 \%$ (Burrows) (Table 2).

Course after admission: The patient complained consistently of dyspnea in the supine position. On lying down he immediately developed severe respiratory difficulty and became very agitated, and arterial oxygen saturation $\left(\mathrm{SpO}_{2}\right)$ decreased from $98 \%$ to $90 \%$ within 1 minute. On careful observation of the patient's thoracic and abdominal movement immediately after changing body position from sitting to supine, paradoxical chest wall movement was noticed. In 
Table 2. Changes of Pulmonary Function Tests over 7 Years

\begin{tabular}{|c|c|c|c|c|c|c|c|}
\hline & & $\begin{array}{c}\text { Sitting } \\
\text { position } \\
\text { (Dec 1996) }\end{array}$ & $\begin{array}{c}\text { Supine } \\
\text { position } \\
\text { (Jan 1997) }\end{array}$ & & & $\begin{array}{c}\text { Sitting } \\
\text { position } \\
\text { (Mar 2003) }\end{array}$ & $\begin{array}{c}\text { Supine } \\
\text { position } \\
\text { (Mar 2003) }\end{array}$ \\
\hline $\mathrm{VC}$ & (L) & 2.81 & 1.58 & $\mathrm{VC}$ & (L) & 3.70 & 3.17 \\
\hline$\% \mathrm{VC}$ & $(\%)$ & 76.1 & - & $\% \mathrm{VC}$ & $(\%)$ & 104.6 & - \\
\hline $\mathrm{FEV}_{1.0}$ & (L) & 1.96 & 1.12 & $\mathrm{FEV}_{1.0}$ & (L) & 2.50 & 2.13 \\
\hline $\mathrm{FEV}_{1.0} / \mathrm{FVC}$ & $(\%)$ & 78.7 & 74.7 & $\mathrm{FEV}_{1.0} / \mathrm{FVC}$ & $(\%)$ & 71.4 & 72.7 \\
\hline TLC & (L) & 4.61 & 2.77 & TLC & (L) & 5.14 & 4.43 \\
\hline $\mathrm{RV}$ & (L) & 1.72 & 1.2 & RV & (L) & 1.44 & 1.26 \\
\hline$\% \mathrm{RV}$ & $(\%)$ & 37.3 & - & $\% \mathrm{RV}$ & $(\%)$ & 28.0 & - \\
\hline FRC & (L) & 2.68 & 1.38 & FRC & (L) & 2.71 & 1.89 \\
\hline$\% \mathrm{MVV}$ & $(\%)$ & 74.0 & - & $\% \mathrm{MVV}$ & $(\%)$ & 107.2 & - \\
\hline$\% \mathrm{DL}_{\mathrm{CO}}$ & $(\%)$ & 96.0 & - & $\% \mathrm{DL}_{\mathrm{CO}}$ & $(\%)$ & 102.8 & - \\
\hline
\end{tabular}

VC: vital capacity, \%VC: \% predicted value of $\mathrm{VC}(2), \mathrm{FEV}_{1.0}$ : forced expiratory volume in one second, FVC: forced vital capacity, TLC: total lung capacity, RV: residual volume, \%RV: \% predicted value of RV (Boren), FRC: functional residual capacity, \%MVV: \% predicted value of maximal voluntary ventilation (Baldwin), $\% \mathrm{DL}_{\mathrm{CO}}$ : \% predicted value of diffusing capacity for carbon monoxide (Burrows)
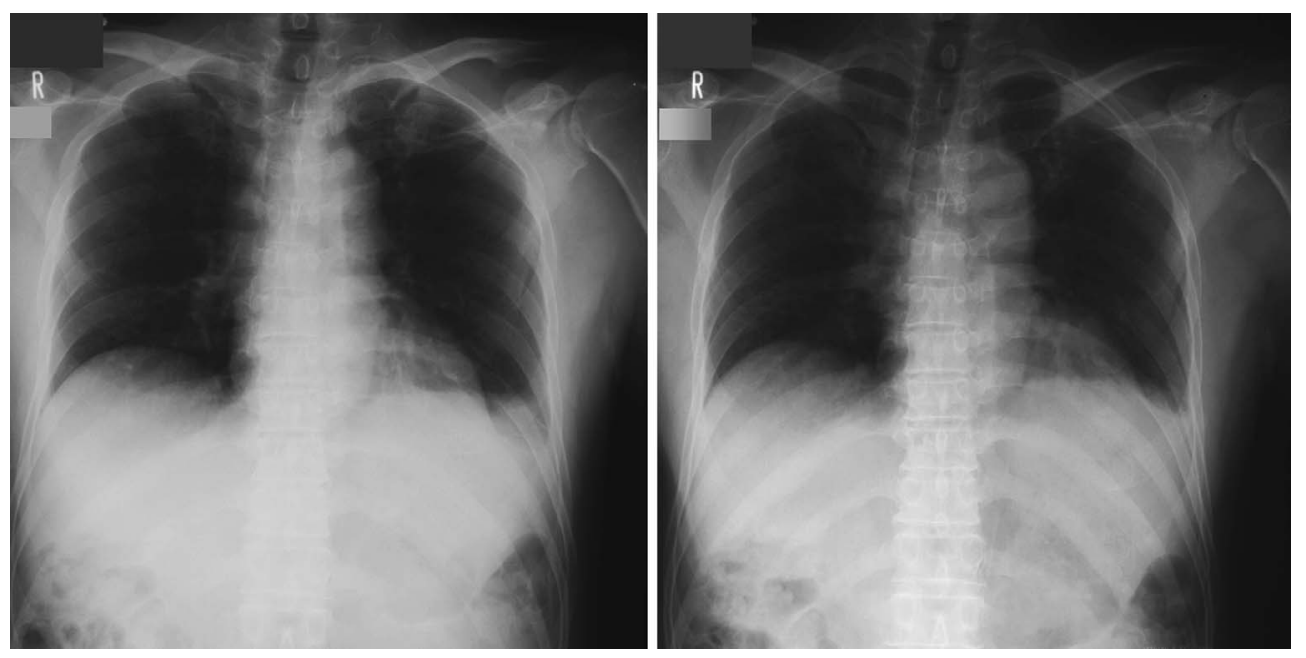

Figure 2. Chest X-rays in the supine position in late December, 1996: (A) In deep inspiration, the diaphragm is elevated higher than that in the standing position as shown in Fig. 1(A). (B) Diaphragm elevated only approximately $1.5 \mathrm{~cm}$ upon deep expiration, in comparison to deep inspiration.

late December the patient was able to maintain the supine position for a short period of time, and X-rays were successfully obtained in the supine position at expiration and inspiration (Fig. 2). In the supine position, the diaphragm displaced cranially into the thorax in comparison to the standing position in maximal inspiration, and moved further cranially approximately $1.5 \mathrm{~cm}$ in maximal expiration, restricting respiratory movement. There was minimal diaphragmatic movement associated with respiration, so BPP was strongly suspected. Chest computed tomography (CT) showed discoid atelectasis in the left lower lobe of the lung, and there were no obvious intrapulmonary or mediastinal lesions. Ventilation-perfusion scanning showed no clear defect images. Ultrasonic cardiography was normal, and there were no shunt lesions. No obvious abnormalities were found on magnetic resonance image (MRI) scans of the head or cervical vertebrae. Polysomnography showed an apnea-hypopnea index of 0.2 (normal) in the semi-supine position in January 1997. Since a bilateral diaphragmatic electromyogram signal was not elicited on a phrenic nerve stimulation test, the patient was diagnosed with BPP. In late January, the patient was able to maintain the supine position for approximately 5 minutes, although this posture was associated with dyspnea. So it was possible to perform pulmonary function tests and blood gas analysis in the supine position (Tables 1, 2). Blood gas analysis revealed hypoxemia, but carbon dioxide partial pressure was normal, ruling out the possibility that the hypoxemia was secondary to BPP-induced alveolar hy- 


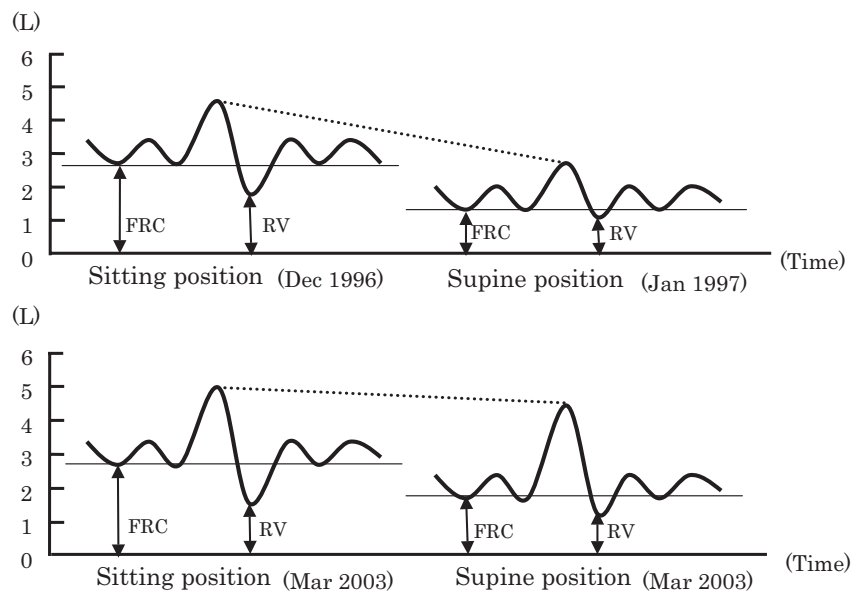

Figure 3. Spirographic changes over 7 years: This figure shows spirographic data from the sitting and supine positions at the beginning and end of the 7-year period. The data show improvement in total lung capacity (TLC), functional residual capacity (FRC), and residual volume (RV) in the supine position after 7 years.

poventilation. In pulmonary function tests, findings for vital capacity (VC), total lung capacity (TLC), functional residual capacity (FRC), and residual volume (RV) obtained in the supine position were approximately $60 \%, 60 \%, 50 \%$, and $70 \%$, respectively in comparison to the corresponding values in the sitting position. However, $\mathrm{FEV}_{1.0} / \mathrm{FVC}$ was nearly normal. The patient's subjective symptoms gradually improved approximately 50 days after admission, with no particular treatment. The patient was able to sleep in Fowler's position and was discharged in early February 1997, after which we monitored his progress as an outpatient. He was able to sleep in the supine position in October 1997, and pulmonary function in the supine position had recovered to the normal range by March 2003 (Table 2, Fig. 3).

\section{Discussion}

BPP is a disease that presents with typical orthopnea. This condition is rare, and is often difficult to diagnose on the first encounter. BPP is characterized by the elevation of both sides of the diaphragm, paradoxical respiratory movement, and increased dyspnea in the supine position (1). Dyspnea is more pronounced than with unilateral phrenic nerve paralysis, and worsens in the supine position. The most important physical sign is paradoxical respiratory movement, often observed in the supine or semi-recumbent position. In this case, BPP was suspected since paradoxical respiratory movement was noticed in the chest wall a few days after admission to our hospital. It appeared that the diaphragm was contracting normally at deep inspiration and deep expiration in the standing position, but deep inspiratory and expiratory chest X-ray revealed little movement of either side of the diaphragm in the supine position. These findings suggested BPP (3). A diagnosis of BPP was made because percutaneous stimulation of the left and right phrenic nerves produced no electrical response from the diaphragm.

The etiology of BPP is attributed to peripheral nerve disease, phrenic nerve injury (4), and idiopathy (5). There are reports of BPP caused by NA, inherited disease (6), diabetes mellitus (7), and systemic lupus erythematosus (8) manifesting as peripheral neuropathy. A detailed interview in this case revealed that the patient had severe pain in both shoulders before he developed dyspnea; thus the cause of BPP was thought to be NA. This condition was reported by Parsonage and Turner in 1948 (9). NA is characterized by sharp pain persisting for a few days in the scapular region, after which the pain disappears and the muscle weakens. Although the lesion is usually unilateral, it can also be bilateral (9). The present patient was diagnosed as having NA only affecting both phrenic nerves, because the patient had severe pain in both shoulders, dyspnea developed 4 days after resolution of the pain, phrenic nerve stimulation at the neck elicited no response on either side, no neurological abnormalities were found except in relation to the phrenic nerves, and there was no evidence of any other disease potentially causing BPP.

None of the above-mentioned reports covered cases of NA complicated with BPP. Comroe et al first reported a case of NA complicated by BPP in 1951 (10). Subsequently, Tsairis et al reported that 6 of 99 patients with NA also had unilateral phrenic nerve paralysis and 1 also had BPP (11). In Japan, there was also a reported case that was thought to have resulted in BPP due to NA (12). The male to female ratio in patients with NA has been reported to be 2.4 : 1 (11). In a report by Mulvey et al, all 12 patients with NA complicated by BPP were men (13), while 4 of 5 such patients were men in a report by Tsao et al (14). In other reports, NA was more frequently complicated by BPP in men than in women $(15,16)$.

The possibility of BPP should always be considered in diagnosing a patient with orthopnea of unknown cause. The mechanism of this orthopnea is related to the action of gravitational forces on the abdominal visceral mass and diaphragm. In healthy persons in the standing position, the abdominal cavity organs and diaphragm are displaced downward due to gravitational forces, but tonic contraction of the abdominal muscles maintains FRC at a fixed level, while the activity of the respiratory muscles, including the diaphragm, provides ventilation. In contrast, in patients with BPP in the standing position, resting ventilation is accomplished by thoracic respiration provided by the activity of the intercostal muscles and the cervical accessory respiratory muscles in the absence of diaphragmatic contraction. Hyperventilation observed in patients with BPP during exercise is maintained by expiration due to the activity of the abdominal muscles (expiratory muscles), followed by passive inspiration due to abdominal muscle relaxation (3). When a patient with BPP assumes the supine position, however, the paralyzed diaphragm is displaced cranially by the hydrostatic force gener- 
ated by the abdominal cavity organs, thereby causing a decrease of FRC and VC. The subsequent, inspiratory effort by the intercostal muscles and accessory respiratory muscle dilates the thorax and accordingly creates more negative intrapleural pressure, resulting in further cranial displacement of the abdominal cavity organs and diaphragm and retraction of the abdominal wall. This causes paradoxical respiratory movement and leads to ventilatory failure (17). Paradoxical respiratory movement can be generated by either diaphragmatic paralysis or paresis, although there are some differences in severity. The transdiaphragmatic pressure was not measured in the present patient, but paralysis appeared to be present because percutaneous stimulation of the left and right phrenic nerve elicited no electrical response from the diaphragm.

There is no specific therapy for NA. Therefore, at the onset of brachial neuralgic pain, reduce the pain by means of anti-inflammatory analgesics, and wait for neural recovery (9). In the case of respiratory failure due to BPP, use of non-invasive positive pressure ventilation (NPPV) assists ventilation $(1,12)$. Regarding the prognosis of NA complicated by BPP, one report noted slight bilateral improvement in diaphragmatic function during the observation period of 1 to 4 years (14), but other reports stated that few cases showed improvement $(13,15)$. It thus can be expected that more time is necessary before diaphragmatic function is restored bilaterally. The present patient developed NA in early May 1996, and slept leaning on a table in the sitting position for about 260 days from that time. He became able to sleep in a semi-supine position from the end of January 1997, and then in the supine position in October 1997, about 18 months after disease onset, and achieved a normal range of lung function by 7 years after disease onset.

In conclusion, it is important to consider the possibilities of bronchial asthma and cardiac failure as well as BPP when making a diagnosis of orthopnea. This case is also of interest because NA should be included as a possible cause of BPP.

\section{References}

1. Rochester DF, Findley LJ. Neuromuscular and skeletal disease. In: Pulmonary Complications of Systemic Disease. Lung Biology in Health and Disease. Vol. 59. Murray JF, Ed. Marcel Dekker, Inc., New York, 1992: 303-384.

2. Pulmonary Physiology Committee of the Japanese Respiratory Society. Standard values of spirogram and arterial blood gas in Japanese. The Journal of the Japanese Respiratory Society 39: 2001 (in Japanese).

3. IY Ch'en, JD Armstrong 2nd. Value of fluoroscopy in patients with suspected bilateral hemidiaphragmatic paralysis. Am J Roentgenol 160: 29-31, 1993.

4. Werner RA, Geiringer SR. Bilateral phrenic nerve palsy associated with open-heart surgery. Arch Phys Med Rehabil 71: 1000-1002, 1990.

5. Pereira MC, Mussi RF, Massucio RA, et al. Idiopathic bilateral diaphragmatic paresis. J Bras Pneumol 32: 481-485, 2006.

6. Hardie R, Harding AE, Hirsch N, et al. Diaphragmatic weakness in hereditary motor and sensory neuropathy. J Neurol Neurosurg Psychiatry 53: 348-350, 1990.

7. White JE, Bullock RE, Hudgson P, Home PD, Gibson GJ. Phrenic neuropathy in association with diabetes. Diabet Med 9: 954-956, 1992.

8. Hardy K, Herry I, Attali V, Cadranel J, Similowski T. Bilateral phrenic paralysis in a patient with systemic lupus erythematosus. Chest 119: 1274-1277, 2001.

9. Parsonage MJ, Turner JWA. Neuralgic amyotrophy. The shouldergirdle syndrome. Lancet 254: 973-978, 1948.
10. Comroe JH Jr, Wood FC, Kay CF, Spoont EM. Motor neuritis after tetanus antitoxin with involvement of the muscles of respiration. Am J Med 10: 786-789, 1951.

11. Tsairis $P$, Dyck PJ, Mulder DW. Natural history of brachial plexus neuropathy. Report on 99 patients. Arch Neurol 27: 109-117, 1972.

12. Kadowaki M, Mizuno S, Uesaka D, et al. A case of bilateral diaphragmatic paralysis clinically suggestive of brachial neuritis. Nihon Kokyuki Gakkai Zasshi 43: 513-517, 2005 (in Japanese, Abstract in English).

13. Mulvey DA, Aquilina RJ, Elliott MW, Moxham J, Green M. Diaphragmatic dysfunction in neuralgic amyotrophy. An electrophysiologic evaluation of 16 patients presenting with dyspnea. Am Rev Respir Dis 147: 66-71, 1993.

14. Tsao BE, Ostrovskiy DA, Wilbourn AJ, Shields RW Jr. Phrenic neuropathy due to neuralgic amyotrophy. Neurology 66: 15821584, 2006.

15. Gregory RP, Loh L, Newsom-Davis J. Recurrent isolated alternating phrenic nerve palsies: a variant of brachial neuritis? Thorax 45: 420-421, 1990.

16. Graham A, Martin PD, Haas LF. Neuralgic amyotrophy with bilateral diaphragmatic palsy. Thorax 40: 635-636, 1985.

17. De Troyer A, Estenne M. The respiratory system in neuromuscular disorders. In: The Thorax Part C: Disease. Lung Biology in Health and Disease. vol.85. Roussos C, Ed. Marcel Dekker, Inc., New York, 1995: 2177-2212.

(C) 2009 The Japanese Society of Internal Medicine http://www.naika.or.jp/imindex.html 